\title{
Scale-dependence of temporal stability of surface-soil moisture in a desert area in northwestern China
}

\author{
Pingping Zhang ${ }^{\mathrm{a}, \mathrm{b}}$, Ming'an Shao ${ }^{\mathrm{a}, \mathrm{b}, \mathrm{c}, *}$, Xingchang Zhang ${ }^{\mathrm{a}, \mathrm{b}}$ \\ ${ }^{a}$ Institute of Soil and Water Conservation, Chinese Academy of Science and Ministry of Water Resources, Yangling 712100, China \\ ${ }^{b}$ State Key Laboratory of Soil Erosion and Dryland Farming on the Loess Plateau, Northwest AEF University, Yangling 712100, China \\ ${ }^{\mathrm{c}}$ Key Laboratory of Ecosystem Network Observation and Modeling, Institute of Geographical Science and Natural Resources, Chinese Academy of Sciences, Beijing 100101, China
}

\section{A R T I C L E I N F O}

\section{Article history:}

Received 23 April 2015

Accepted 10 May 2015

Available online 16 May 2015

This manuscript was handled by

Konstantine P. Georgakakos, Editor-in-Chief, with the assistance of Marco Borga,

Associate Editor

\section{Keywords:}

Sampling scales

Re-sampling method

Temporal stability

Soil moisture

Desert ecosystems

\begin{abstract}
S U M M A R Y
Soil moisture is an important component in hydrological cycles but is highly variable in space and time. As a tool for optimal soil and water management and effective field monitoring, the analysis of temporal stability has recently received increasing interest. The scale dependence of temporal stability, however, has received little attention. We measured surface-soil $(0-6 \mathrm{~cm})$ moisture at 187 sampling locations in a desert region $\left(40 \mathrm{~km}^{2}\right)$ in northwestern China approximately every two weeks from April to October 2012 with a Theta Probe, for a total of 13 sampling campaigns. We grouped the samples by re-sampling analysis under six sampling spacings and six different sizes of sampling area (extents) to analyse the changes in the characteristics of temporal stability at the various sampling scales and to test the accuracy of the field-mean moisture content estimated by measurements at a limited number of locations at each sampling scale. Increasing the spacing had little influence on the temporal stability of both the overall spatial pattern and the individual locations, whereas increasing the extent tended to increase the temporal stability of the overall spatial pattern but to decrease the temporal stability at the individual locations. The characteristics of temporal stability were susceptible to changes in scale when extent was small. Exponential and power equations could well express the relationships between most of the parameters of temporal stability and sampling scale. The number of identified representative locations (RLs) was influenced by sample size and was more sensitive to changes in sample size caused by extent than by spacing. At all sampling scales, the sets of selected RLs accurately estimated the field mean for the entire study period by using offset estimates, and the estimate accuracy was not affected by sampling scale. Increasing the spacing did not change the influence of topography and soil properties on temporal stability, whereas increasing the extent tended to intensify the influence of relative elevation and soil organic carbon content but to weaken the influence of saturated hydraulic conductivity on temporal stability. This study contributes to our understanding of the dependence of temporal stability of soil moisture in desert ecosystems on sampling scale and will help the integration of information from different spatial scales and the design of optimal sampling sizes and strategies for similar studies.
\end{abstract}

(c) 2015 Published by Elsevier B.V.

\section{Introduction}

Surface-soil moisture is a key component of the hydrological cycle (Choi and Jacobs, 2007; Heathman et al., 2012). It plays an active role in controlling the exchange of water and energy between the land surface and the atmosphere (Vereecken et al., 2007; Sur et al., 2013; Vereecken et al., 2014). In arid desert environments, it also acts as a key factor limiting the growth of

* Corresponding author at: Key Laboratory of Ecosystem Network Observation and Modeling, Institute of Geographical Sciences and Natural Resources Research, Chinese Academy of Sciences, Beijing 100101, China. Fax: +86 2987012210.

E-mail address: mashao@ms.iswc.ac.cn (M. Shao). vegetation (Thornes, 1985), and its dynamics largely control the spatial and temporal distribution of vegetation and the restoration and reconstruction of degenerated ecosystems (Berndtsson et al., 1996; Rodriguez-Iturbe et al., 1999). Soil moisture, however, is highly variable in space and time across different scales, so characterising the behaviour of soil moisture can be challenging (Vereecken et al., 2007).

The analysis of the temporal stability of soil moisture is receiving increasing interest. This concept was first introduced by Vachaud et al. (1985) and is a reflection of the temporal persistence of the spatial structure (Kachanoski and Jong, 1988). This method can identify representative temporally stable locations that can predict the field-mean soil moisture over long periods and can thus 
help to optimise soil and water management and effective field monitoring (Martínez-Fernández and Ceballos, 2003). Variable soil moisture at a location is due to the operation and interaction of underlying hydrological processes at different spatial scales, so the spatial variability of soil moisture is often a function of scale (Famiglietti et al., 2008). Kachanoski and Jong (1988) thus extended the concept of temporal stability with an analysis of spatial coherence and indicated that the temporal stability was also strongly scale dependent. An adequate understanding of this scale dependence is the basis for the integration of information from different spatial scales (Western and Blöschl, 1999) and would be extremely beneficial for developing efficient and effective strategies of soil sampling for the validation of remote-sensing techniques and the application of some climate and hydrological models (Starks et al., 2003; Mittelbach and Seneviratne, 2012).

The temporal stability of soil moisture has been determined for different purposes over a wide range of scales, from field and hillslope scales to watershed and regional scales. The characteristics of temporal stability, however, can vary greatly between scales. For example, Zhao et al. (2010), Brocca et al. (2009) and Coppola et al. (2011) investigated the temporal stability of the spatial patterns of surface-soil moisture at field scales $\left(225-8800 \mathrm{~m}^{2}\right)$ and found that the range of mean relative difference (MRD) (Eqs. (1) and (2))was low, generally 20-60\%. Grayson and Western (1998) and Cosh et al. (2006), however, reported that the ranges of MRD in 27 and $610 \mathrm{~km}^{2}$ watersheds were approximately 95\% and $170 \%$, respectively. Bosch et al. (2006) reported that the range of MRD exceeded $200 \%$ in a $3750 \mathrm{~km}^{2}$ coastal plain in the United States. The range of MRD thus appears to increase with the size (hereafter, extent) of the study area. Conflicts and divergences, however, have also been reported. For example, Hu et al. (2010) observed that the range of MRD was over $170 \%$ in a small watershed (20 ha), whereas Brocca et al. (2012) found that the range of MRD was only approximately $50 \%$ in two larger watersheds $\left(178\right.$ and $242 \mathrm{~km}^{2}$ ). Contradictory results have also been reported for other characteristics of temporal stability, such as the standard deviation of relative difference (SDRD) (Eqs. (3) and (4)) and Spearman's rank correlation coefficient $\left(r_{s}\right)$ (Eq. (5)). Obtaining a clear picture of the characteristics of temporal stability at different scales by simple comparisons of the achieved results is thus difficult, because various studies differ not only in sampling scales but also in environmental conditions, layout of the experiments, and measurement techniques (Vanderlinden et al., 2012). These differences strongly hinder the application of the results to different scales. Systematic study of the effect of scale on the characteristics of temporal stability is thus necessary.

Given the importance of soil moisture in desert ecosystems, the characteristics of the temporal stability of soil moisture at one scale have been preliminarily studied in various desert regions, but little information is available for multiple scales. Whether the temporal stability can be maintained under increasing scale remains unknown. We thus measured surface-soil moisture in a $40 \mathrm{~km}^{2}$ desert region on 13 occasions from April to October 2012. Re-sampling method was then employed with changing sampling scale (spacing and extent), and the characteristics of temporal stability for each scenario were determined. The objectives of this study were (1) to provide a better understanding of the variation in the characteristics of temporal stability with increasing sampling scales, (2) to test the accuracy of the field-mean moisture content estimated at each sampling scales by using the concept of temporal stability, and (3) to analyse the changes in contributions of topography and soil properties to the temporal stability with changing sampling scales. These objectives could provide a scientific basis for designing efficient sampling schemes, integrating information from different spatial scales, and allowing upscaling in hydrological models.

\section{Materials and methods}

\subsection{Study area and data collection}

The experiment was conducted in a desert area in the central reaches of the Heihe River Basin in Gansu Province in northwestern China (Fig. 1). The topography is relatively flat, with an average elevation of ca. $1421 \mathrm{~m}$ a.s.l. The area is characterised by an arid desert climate, with a mean annual precipitation of $117 \mathrm{~mm}$, temperature of $7.6^{\circ} \mathrm{C}$, and pan evaporation of $2390 \mathrm{~mm}$. Precipitation is highly variable throughout the year, with nearly $65 \%$ falling during July and September. The zonal soil has been classified as a gray-brown desert soil, and the soil texture is quite spatially heterogeneous, ranging from sand to clay. The vegetative cover is approximately $5-15 \%$, and the main species are discontinuous sub-shrubs, such as Nitraria sphaerocarpa Maxim. and Reaumuria soongorica (Pall.) Maxim.

The study area is approximately $40 \mathrm{~km}^{2}(8 \mathrm{~km} \times 5 \mathrm{~km})\left(39^{\circ} 24^{\prime}\right.$ to $39^{\circ} 28^{\prime} \mathrm{N}$ and $100^{\circ} 08^{\prime}$ to $100^{\circ} 11^{\prime} \mathrm{E}$ ), bordered by a young oasis to the southwest, a remnant of the Qilian Mountains to the north, and an extension of the Badain Jaran Desert to the southeast (Fig. 1c). Wooden stakes were set on a regular $500 \mathrm{~m} \times 500 \mathrm{~m}$ grid throughout the area at a total of 187 locations for measurements of soil moisture. Each location was positioned with a portable Garmin GPS receiver (with a resolution of $3 \mathrm{~m}$ ). A Theta Probe (Type ML2x, Delta-T Devices, Cambridge, UK) was inserted vertically in the soil to measure the surface $(0-6 \mathrm{~cm})$ volumetric soil moisture content approximately every two weeks from 15 April to 15 October 2012, providing a spectrum of moisture conditions ranging from dry to wet. A total of 13 sampling campaigns were conducted. To reduce the possible influence of micro-scale variability, three replicate measurements were conducted within a radius of approximately $10 \mathrm{~cm}$ for each location and campaign. Detailed information on the calibration of the probe can be found in Zhang and Shao (2013).

Disturbed and undisturbed soil samples were collected from the 0 to $6 \mathrm{~cm}$ soil layer at each location. The disturbed samples were used for measuring soil particle size distribution and soil organic carbon (SOC, g/kg) content. Soil particle sizes were evaluated using the Mastersizer2000 apparatus manufactured by Malvern, and SOC content was measured by using the potassium dichromate-wet combustion method (Nelson and Sommers, 1982). The undisturbed samples were used for determining saturated hydraulic conductivity (Ks, $\mathrm{mm} / \mathrm{min}$ ), using the constant hydraulic head method (Klute and Dirksen 1986), and determining soil bulk density, (BD, g/ $\mathrm{cm}^{3}$ ) and total porosity (TP, \%), using the gravimetrical method.

\subsection{Analysis of temporal stability}

We evaluated the temporal stability of soil moisture by two statistical approaches. First, the temporal stability of individual locations was determined using an analysis of relative differences (Vachaud et al., 1985). This approach compares the soil-moisture content at a particular location to the mean over the entire study area and determines if it is consistently higher or lower than the mean and the variability of this relationship. The relative difference, $\delta_{i j}$, of the soil-moisture content, $\theta_{i j}$, for each location $i$ is calculated as:

$\delta_{i j}=\frac{\theta_{i j}-\overline{\theta_{j}}}{\overline{\theta_{j}}}$

where $\overline{\theta_{j}}$ is the mean soil-moisture content over the entire area on sampling occasion $j$ :

$\overline{\theta_{j}}=\frac{1}{N} \sum_{i=1}^{N} \theta_{i j}$ 

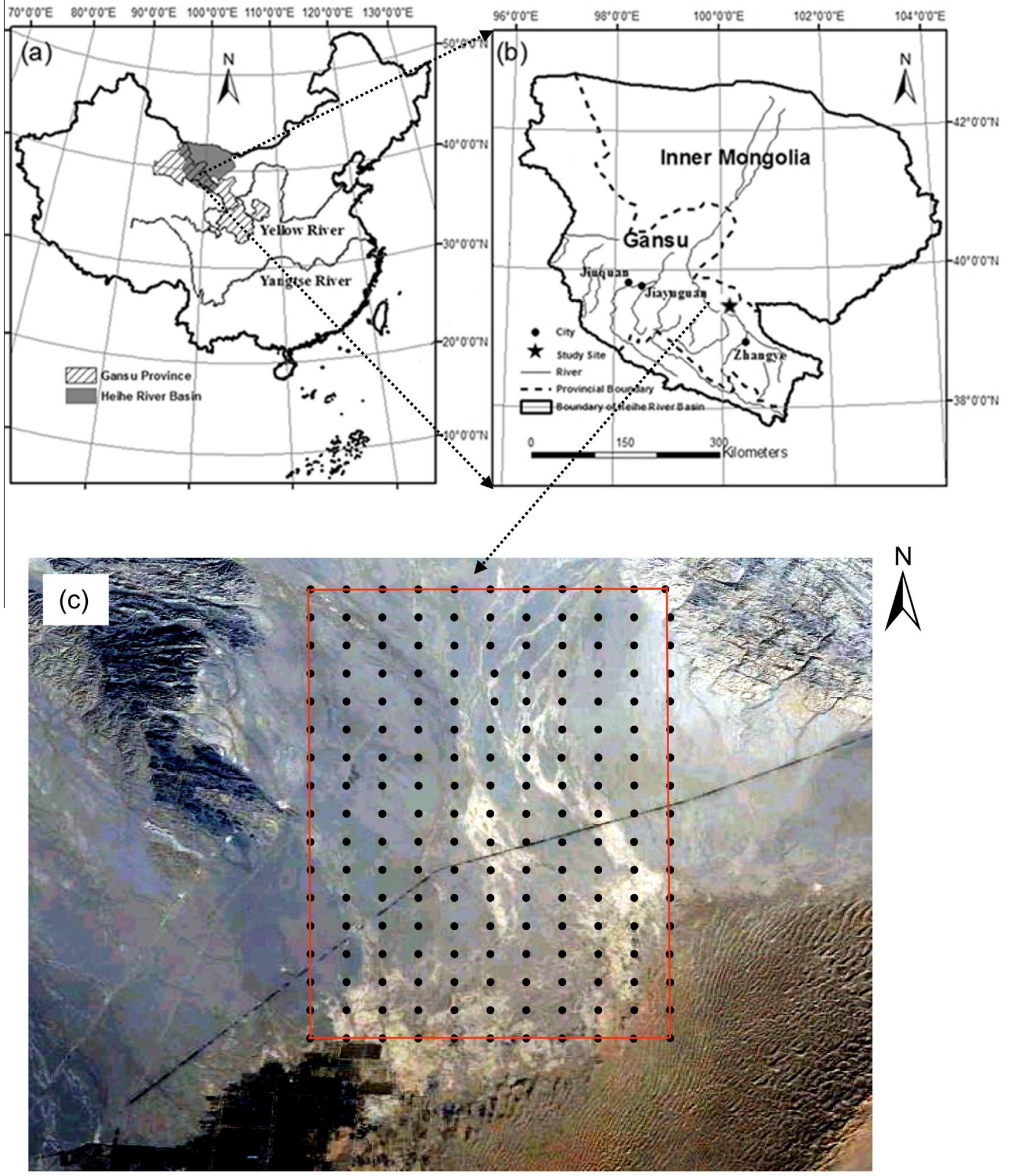

Fig. 1. The location of Gansu Province and the Heihe River Basin, China (a), the study area in the Heihe River Basin (b), and the soil sampling locations in the study area (c).

The MRD, $\overline{\delta_{i}}$, and SDRD, $\sigma\left(\delta_{i}\right)$, over the sampling period for each location are calculated by:

$\overline{\delta_{i}}=\frac{1}{M} \sum_{j=1}^{M} \delta_{i j}$

$$
\sigma\left(\delta_{i}\right)=\sqrt{\frac{1}{M-1} \sum_{j=1}^{M}\left(\delta_{i j}-\overline{\delta_{i}}\right)^{2}}
$$

where $M$ is the total number of sampling occasions. Locations with $\bar{\delta}_{i}$ near zero can accurately estimate the field-mean moisture 
content, whereas locations with $\overline{\delta_{i}}$ higher or lower than zero overor underestimate the field-mean moisture content, respectively. A lower $\sigma\left(\delta_{i}\right)$ at a location indicates a greater tendency of that location of being temporally stable.

Second, the persistence of the location ranks over time was tested using the nonparametric Spearman's rank correlation (Vachaud et al., 1985), which evaluated the persistence of the spatial patterns of soil moisture across the area. The nonparametric correlation coefficient is expressed as:

$r_{s}=1-\frac{6 \sum_{i=1}^{N}\left(R_{i j}-R_{i j^{\prime}}\right)^{2}}{N\left(N^{2}-1\right)}$

where $R_{i j}$ and $R_{i j^{\prime}}$ are the ranks of the soil moisture at location $i$ at times $j$ and $j^{\prime}$, respectively, and $N$ is the number of locations. The closer $r_{s}$ is to 1 , the higher the temporal stability of the spatial pattern of soil moisture across the study area.

\subsection{Estimating field-mean moisture content}

Locations characterised by a near-zero MRD and a low SDRD can be considered as representative locations (RLs) and can be directly used to estimate the field-mean moisture content (Vachaud et al., 1985). Locations having a near-zero MRD, however, may not be temporally stable. The tradeoff between the two is difficult. Grayson and Western (1998), though, demonstrated that temporally stable locations with non-zero MRDs could be used to represent the field mean when applied with a constant offset $\left(\overline{\delta_{i}}\right)$. In this approach, the field mean can be estimated by:

$\overline{\theta_{j}^{\prime}}=\frac{\theta_{i j}}{1+\overline{\delta_{i}}}$

The root mean square error (RMSE) for assessing the offset estimates of the field mean at the RLs was calculated as:

RMSE $=\sqrt{\frac{1}{M} \sum_{i=1}^{M}\left(O_{i}-P_{i}\right)^{2}}$

where $O_{i}$ and $P_{i}$ are the observed and estimated field means, respectively. The closer the RMSE is to zero, the less error in the offset estimate.

\subsection{Re-sampling method}

Blöschl and Sivapalan (1995) suggested that the sampling scale be termed as a scale triplet consisting of spacing, extent, and support. In field studies, the scale of the support is usually determined by the measurement technique and has little effect on the results. Support was thus not considered in the present study. We only varied the sampling extents and spacings and examined their effects on temporal stability. Western and Blöschl (1999) defined the scale in terms of the spacing, $S$, as the average spacing between the locations, and the scale in terms of the extent, $E$, as the square root of the area of the region. These parameters are expressed as:

$S=\left(\frac{A}{N}\right)^{1 / 2}$

$E=A^{1 / 2}$

where $A$ is the area of the region and $N$ is the number of locations.

A total of six sampling spacings and six sampling extents were established through a re-sampling method. For the spacing, different numbers of locations were drawn randomly from the full dataset to vary the average spacings. Assuming $n$ locations are sampled, it can result in $m$ realisations by using the random sampling without replacement method (Western and Blöschl, 1999). The temporal stability is then analysed for each realisation, and the parameters of temporal stability at this spacing are estimated as the arithmetic average of the $m$ realisations. For example, the first scenario used all locations $(n=187)$. For the next scenario, half of the number of locations $(n=93)$ was used, with $m=2$ temporal stabilities being estimated and their parameters averaged, and so forth until a minimum value of $n=6$ locations (Table 1 ).

For the extent, the first scenario was also based on all locations. The region was then divided into two equal sub-regions, and the data from each sub-region were treated as one realisation. The temporal stabilities were analysed for each of these two realisations, and the parameters of temporal stability at this extent were estimated from the arithmetic averages of the parameters of the two realisations. In the next scenario, the two sub-regions were further subdivided into four sub-regions and so on, until the original region was divided into 32 sub-regions of equal area. In the last scenario, each sub-region contained only nine locations (Table 1 ).

\section{Results and discussion}

3.1. Influence of sampling scale on the temporal stability of soil moisture at the field scale

The temporal persistence of the spatial pattern of soil moisture at the field scale was characterised using the Spearman's rank correlation test. The results for the various sampling scales are given

Table 1

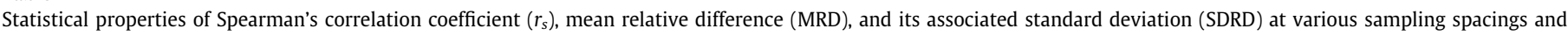
extents.

\begin{tabular}{|c|c|c|c|c|c|c|c|c|c|c|c|c|c|c|}
\hline \multirow[t]{2}{*}{ Sampling scale } & & \multirow[t]{2}{*}{ Sample size } & \multicolumn{5}{|l|}{$r_{s}$} & \multicolumn{3}{|c|}{ MRD (\%) } & \multicolumn{4}{|c|}{ SDRD (\%) } \\
\hline & & & Min. & Max. & Mean & SD & CV (\%) & Min. & Max. & Range & Min. & Max. & Mean & Range \\
\hline \multirow[t]{6}{*}{ Sampling spacing (km) } & 0.46 & 187 & 0.65 & 0.98 & $0.80 \mathrm{a}$ & 0.08 & 9.48 & -45.38 & 167.15 & 212.53 & 6.02 & 92.63 & $18.12 \mathrm{a}$ & 86.61 \\
\hline & 0.66 & 93 & 0.63 & 0.98 & $0.80 a$ & 0.08 & 9.98 & -44.23 & 158.38 & 202.61 & 6.52 & 73.19 & $18.09 a$ & 66.67 \\
\hline & 0.93 & 46 & 0.58 & 0.99 & $0.79 a$ & 0.09 & 11.45 & -43.83 & 143.18 & 187.01 & 6.43 & 61.62 & $17.98 a$ & 55.18 \\
\hline & 1.32 & 23 & 0.57 & 0.98 & $0.79 a$ & 0.09 & 11.70 & -41.30 & 121.07 & 162.37 & 7.48 & 47.35 & 17.59a & 39.88 \\
\hline & 1.75 & 13 & 0.49 & 0.99 & $0.81 \mathrm{a}$ & 0.12 & 15.47 & -40.64 & 95.22 & 135.86 & 8.13 & 37.86 & 17.16a & 29.73 \\
\hline & 2.58 & 6 & 0.22 & 1.00 & $0.72 b$ & 0.19 & 31.89 & -33.50 & 54.57 & 88.07 & 9.43 & 27.56 & $16.07 a$ & 18.14 \\
\hline \multirow[t]{6}{*}{ Sampling extent (km) } & 40 & 187 & 0.65 & 0.98 & $0.80 \mathrm{~A}$ & 0.08 & 9.48 & -45.38 & 167.15 & 212.53 & 6.02 & 92.63 & $18.12 \mathrm{~A}$ & 86.61 \\
\hline & 20 & 99 & 0.58 & 0.98 & $0.77 \mathrm{~B}$ & 0.10 & 12.58 & -41.64 & 123.31 & 164.95 & 4.27 & 76.87 & $17.36 \mathrm{AB}$ & 72.61 \\
\hline & 10 & 54 & 0.55 & 0.98 & $0.76 \mathrm{~B}$ & 0.10 & 14.14 & -39.48 & 91.94 & 131.42 & 6.91 & 56.20 & $16.78 \mathrm{AB}$ & 49.29 \\
\hline & 5 & 30 & 0.47 & 0.98 & $0.75 B C$ & 0.12 & 17.18 & -37.66 & 80.65 & 118.30 & 7.17 & 43.60 & $16.47 \mathrm{ABC}$ & 36.43 \\
\hline & 2.5 & 15 & 0.32 & 0.98 & $0.72 \mathrm{C}$ & 0.16 & 25.64 & -34.88 & 63.99 & 98.87 & 8.02 & 34.26 & $15.82 \mathrm{BC}$ & 26.24 \\
\hline & 1.3 & 9 & 0.21 & 0.99 & $0.69 \mathrm{D}$ & 0.19 & 33.70 & -31.32 & 54.17 & 85.49 & 8.32 & 28.76 & $15.14 \mathrm{C}$ & 20.45 \\
\hline
\end{tabular}

Min., minimum; Max., maximum; SD, standard deviation; CV, coefficient of variation.

Means followed by the same letter are not significantly different $(\alpha=0.05)$ at the various sampling spacings or extents using the least significant difference method. 
in Table 1 , and the changes in $r_{\mathrm{s}}$ with increasing sampling spacing and extent are shown in Fig. 2. Both sampling spacing and extent had profound influence on the statistical assessments of $r_{s}$ (Table 1 and Fig. 2). The minimum value of $r_{s}$ decreased linearly $(p<0.01$, Fig. 2a), and maximum value increased linearly ( $p<0.01$, Fig. 2 b) as spacing increased. These trends were due to the high sensitivity of $r_{s}$ to the number of locations (Cosh et al., 2004, 2008), which decreased as spacing increased, increasing the chances of anomalous extreme values of $r_{s}$ to occur. Some studies have thus recommended using correlation coefficients instead of $r_{s}$ to assess the temporal stability of the spatial patterns of soil moisture (Cosh et al., 2004, 2008; Ran et al., 2009).

The decreasing rate of the minimum $r_{s}$ was greater than the increasing rate of the maximum, so the mean $r_{s}$ tended to decrease with increasing sampling spacing (Fig. 2c), but it is not statistically significant $(p=0.07)$. Analyses of variance (ANOVAs) of $r_{s}$ indicated that spacing significantly influenced the mean $r_{s}$ $(p<0.05)$, but only a few spacings differed significantly (Table 1$)$. These results indicated that sampling spacing had little influence on the characteristics of temporal stability at the field scale. Properly increasing the spacing to reduce the number of locations for a given desert area would thus be advantageous when ascertaining the temporal stability of the spatial pattern of soil moisture over time.

Contrary to sampling spacing, the minimum value of $r_{s}$ increased $(p<0.01$, Fig. 2 f), and the maximum value decreased $(p<0.05$, Fig. $2 \mathrm{~g}$ ) as extent increased, and could be well described as logarithmical functions. The mean $r_{s}$ significantly increased with increasing sampling extent ( $p<0.01$, Fig. 2 h), indicating a stronger temporal persistence in the spatial pattern of soil moisture in larger areas. The number of locations subsequently increases as extent increases, and if an individual location has an anomalous
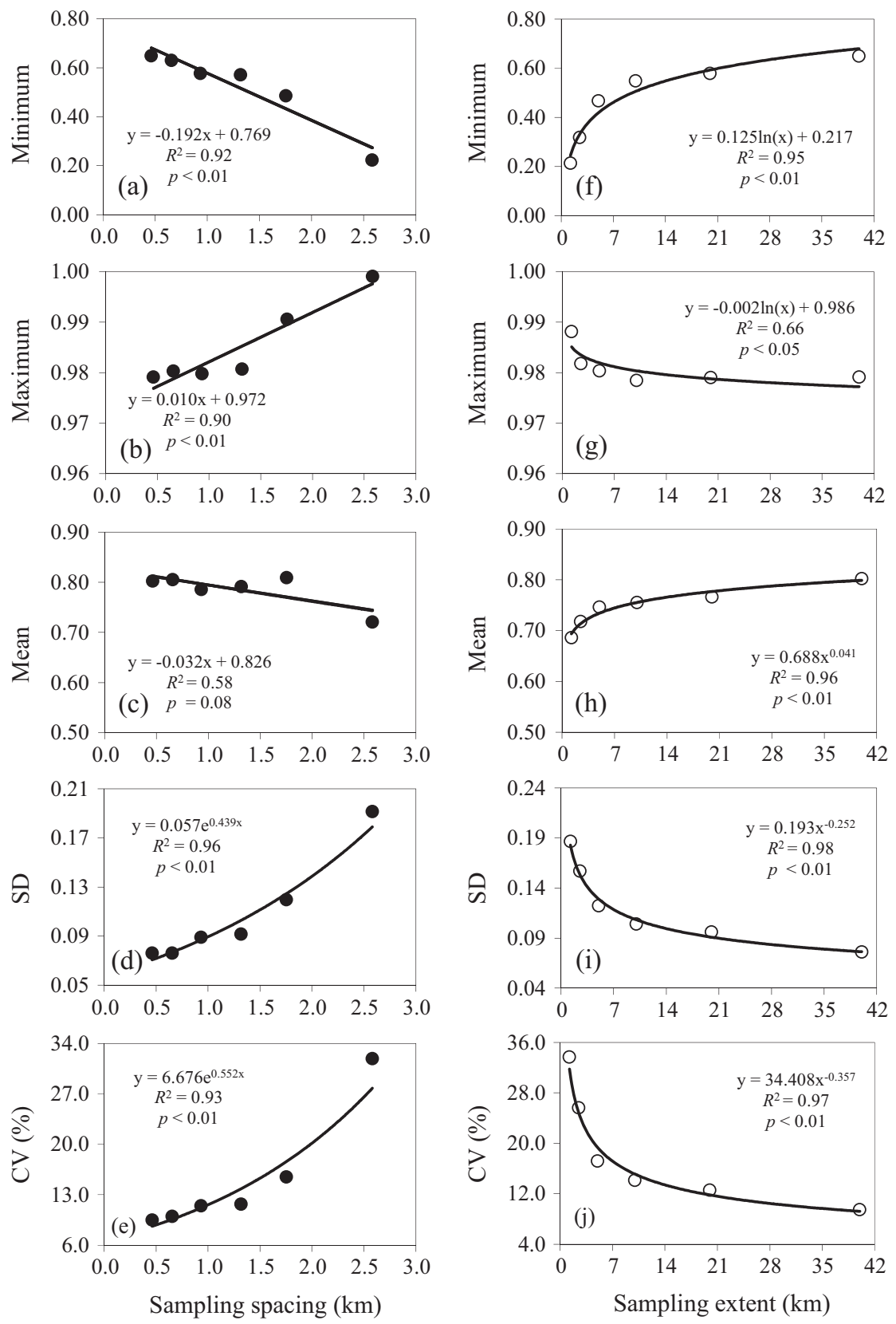

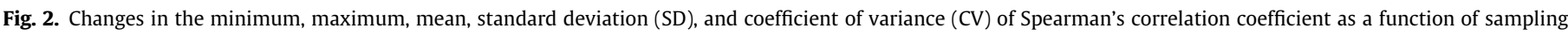
spacing (a-e) and extent $(f-j)$. 
value, its change in rank will not affect the overall rank of the locations. This influence, however, was not uniform at the different scales. The negative power-function relationship between the mean and extent (Fig. 2h) indicated that the temporal stability was more easily affected by changes in extent in small areas than in large areas.

The standard deviation (SD) and coefficient of variance (CV) of $r_{s}$ refers to the variation of $r_{s}$ with different time lags. As others (Schneider et al., 2008; Biswas and Si, 2011; Jia and Shao, 2013; Penna et al., 2013; Zhang and Shao, 2013) have suggested, the temporal stability of the spatial patterns of soil moisture has a time-associated drift, with higher rank correlations between sampling series close in time and decreasing with increasing time lags. The effect of time lags on the temporal patterns of soil moisture was evidently influenced by the spacing and extent, as shown in Fig. $2 \mathrm{~d}$, e and $\mathrm{i}$ and $\mathrm{j}$. The variability of $r_{s}$ increased with an exponential function as spacing increased and decreased with a power-function as extent increased. These relationships implied that the patterns of soil moisture could persist longer in small spacings than in large spacings, and longer in large areas than in small areas.

\subsection{Influence of sampling scale on the temporal stability of soil moisture at the location scale}

The chance that a location with an extreme soil-moisture content is sampled will decrease as sampling spacing increases. The minimum MRD thus increased, and the maximum and range of MRD decreased as spacing increased (Table 1 and Fig. 3a-c). The changes in these statistical parameters with sampling spacing could be best fitted with linear functions $(p<0.01)$. The maximum and range of MRD, however, could also be fitted well with exponential functions ( $p<0.01$, Fig. $3 b$ and $c$ ). Exponential functions may be more theoretically reasonable, because the maximum MRD will decrease uniformly with a linear function as spacing increases, and when the spacing increases to a certain value (about $3.54 \mathrm{~km}$ in this study), the maximum MRD will become negative, which is impossible. In contrast, the maximum MRD will decrease progressively slower with an exponential function as spacing increases to a rate close to zero. The maximum and range of MRD in this study were $21.4 \%$ and $42.2 \%$, respectively, when the spacing increased to the maximum (ca. $4.47 \mathrm{~km}$ ).

The minimum MRD decreased and the maximum and range of MRD increased as sampling extent increased (Table 1 and Fig. 3d-f), indicating an increasing variability of soil moisture with increasing extent, in agreement with other studies (Mohanty and Skaggs, 2001; Martínez-Fernández and Ceballos, 2003; Brocca et al., 2009). Since the factors influencing the variability of soil moisture are scale dependent, the sources of variability of soil moisture, such as parental material, topography, and climate, may become increasingly complex and heterogeneous as extent increases, thereby contributing to higher variability (Zhang and Shao, 2013). For a specific study area, however, the factors influencing the variability of soil moisture cannot increase without limit, so the increasing trend of variability of soil moisture will be moderated and will gradually tend to become relatively stable when the extent increases to a certain level, as indicated by the power-function relationships between extent and the statistical parameters of MRD ( $p<0.01$, Fig. $3 d-f)$.

SDRD serves as an indicator of the temporal persistence of fluctuations of soil-moisture content between individual locations and the field mean. Locations with low SDRDs closely follow the temporal pattern of the field mean (Vachaud et al., 1985). Increasing the sampling spacing increased the minimum SDRD but decreased the maximum and range of SDRD and the relationships between them, and the spacing had significant exponential functions $(p<0.01$, Table 1 and Fig. $4 a-d)$. The decreasing rate of the maximum SDRD was much greater than the increasing rate of the minimum (Fig. 4a-b), indicating that the maximum SDRD is more susceptible to changes in spacing than the minimum. This result
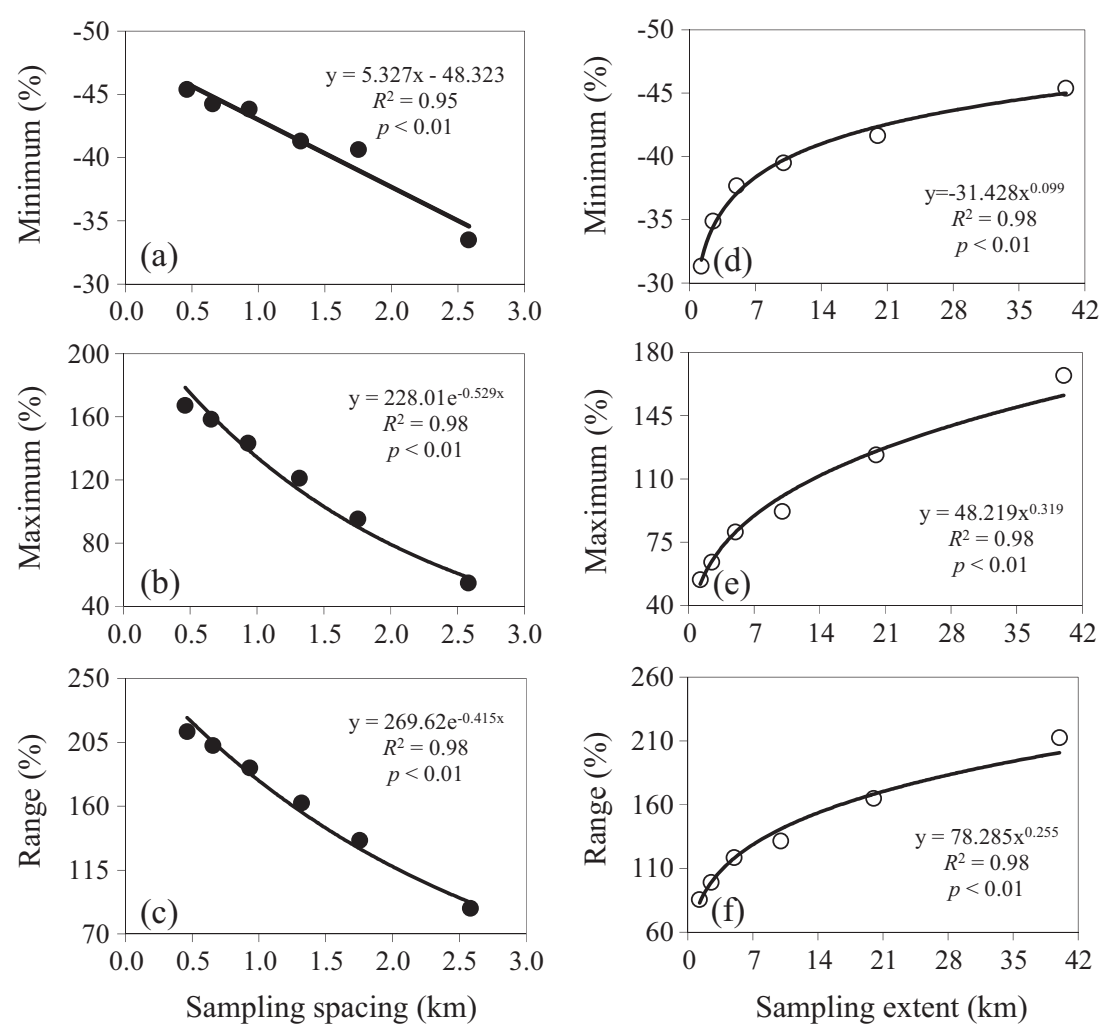

Fig. 3. Changes in the minimum, maximum, and range of the mean relative difference as a function of sampling spacing (a-c) and extent (d-f). 

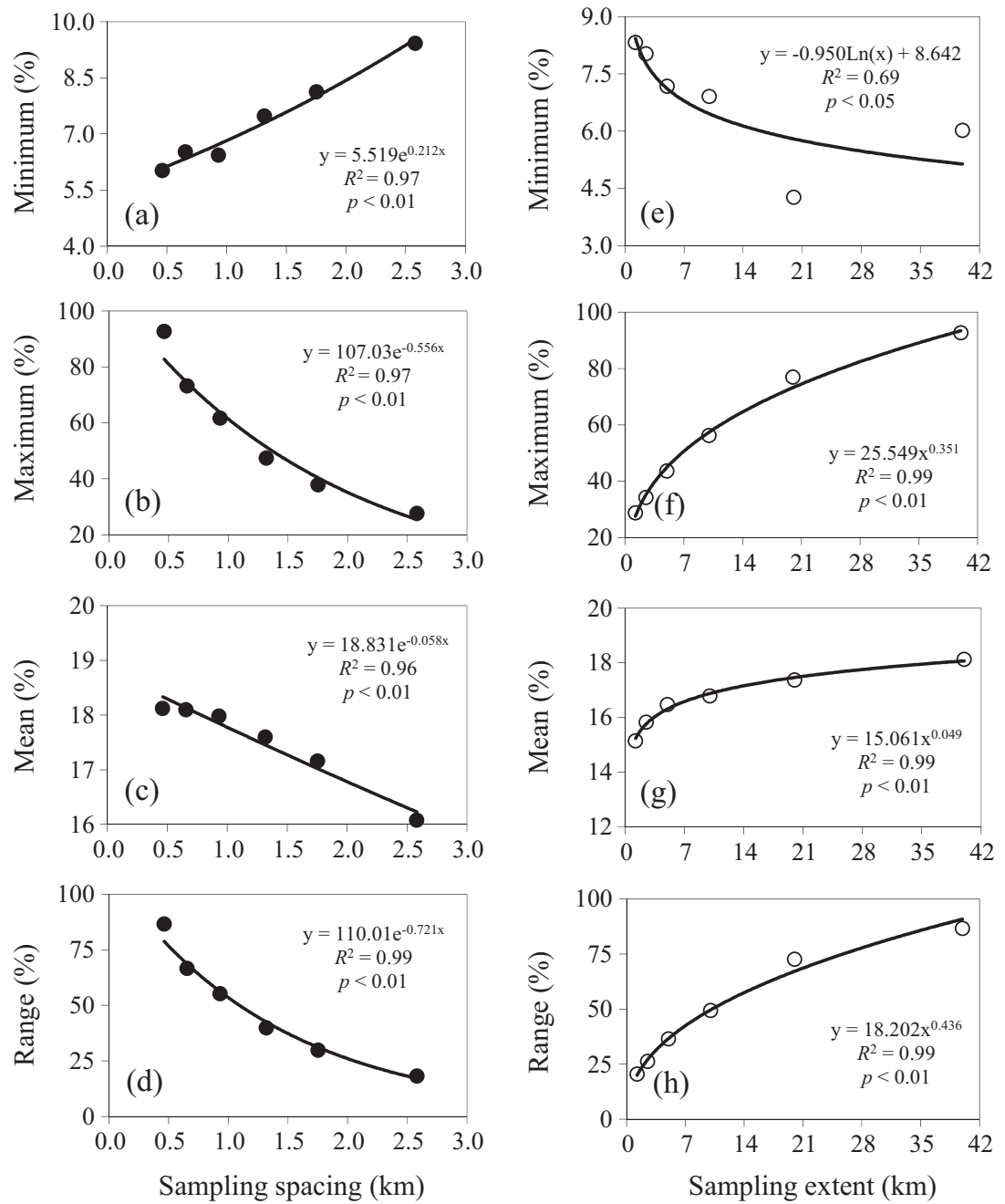

Fig. 4. Changes in the minimum, maximum, mean, and range of the standard deviation of relative difference as a function of sampling spacing (a-d) and extent (e-h)
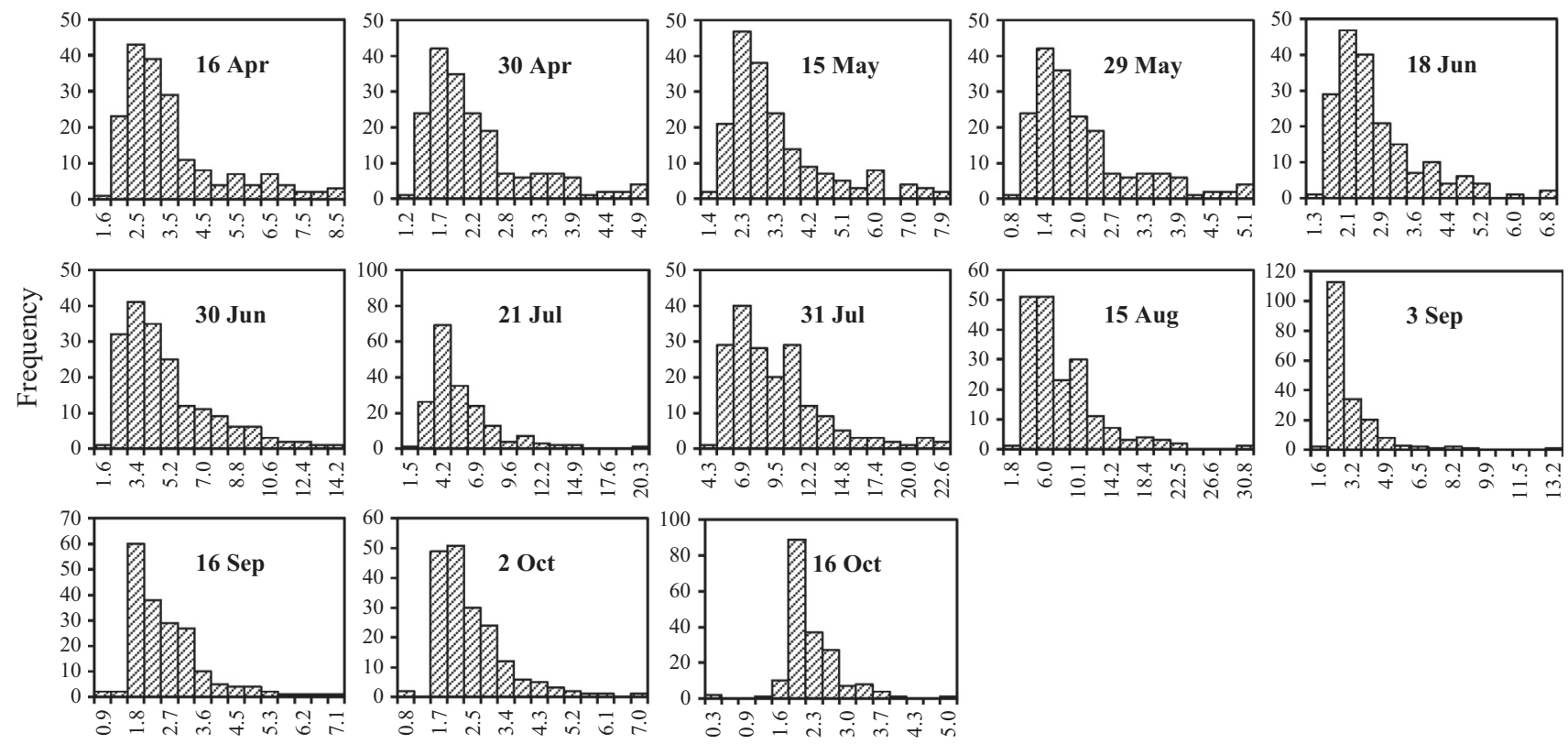

Soil moisture content $(\%)$

Fig. 5. Frequency histograms of soil moisture content at different sampling dates. 

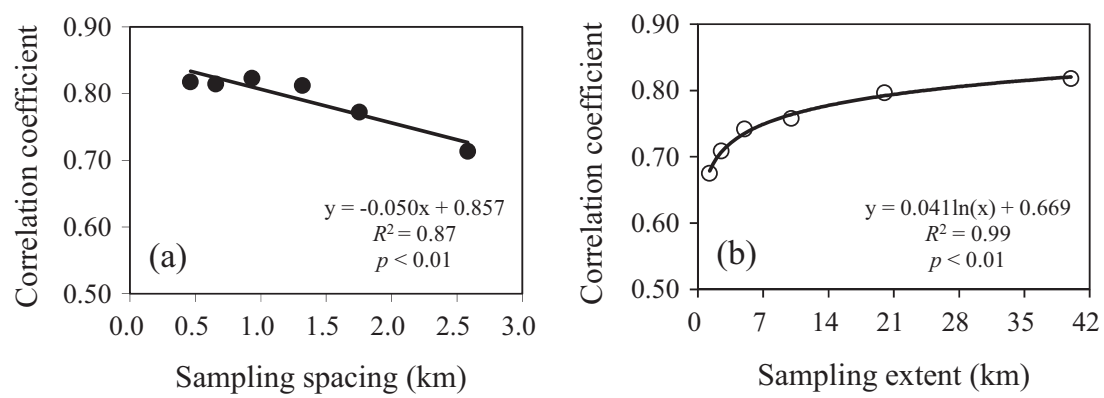

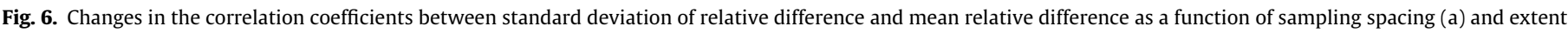
(b).

Table 2

Sample size, number of representative locations (RLs), and root mean square errors (RMSEs) of the offset estimates of the field-mean moisture content by using all RLs (RMSE1) and the most temporally stable RLs (RMSE2) at the various sampling spacings and extents.

\begin{tabular}{clllll}
\hline Sampling scale & & $\begin{array}{l}\text { Sample } \\
\text { size }\end{array}$ & $\begin{array}{l}\text { Number } \\
\text { of RLs }\end{array}$ & $\begin{array}{l}\text { RMSE1 (\% } \\
\text { vol/vol) }\end{array}$ & $\begin{array}{l}\text { RMSE2 (\% } \\
\text { vol/vol) }\end{array}$ \\
\hline Sampling & 0.46 & 187 & 23 & 0.27 & 0.38 \\
spacing (km) & 0.53 & 93 & 12 & 0.29 & 0.36 \\
& 0.65 & 46 & 7 & 0.31 & 0.32 \\
& 0.74 & 23 & 3 & 0.44 & 0.42 \\
& 0.86 & 13 & 2 & 0.43 & 0.41 \\
Sampling & 1.22 & 6 & 2 & 0.46 & 0.50 \\
extent $(\mathrm{km})$ & 40 & 187 & 23 & 0.27 & 0.38 \\
& 20 & 99 & 18 & 0.28 & 0.23 \\
& 10 & 54 & 10 & 0.35 & 0.39 \\
& 5 & 30 & 6 & 0.34 & 0.36 \\
& 2.5 & 15 & 3 & 0.31 & 0.48 \\
& 1.3 & 9 & 4 & 0.31 & 0.49 \\
\hline
\end{tabular}

may have been due to the positively skewed distribution of soil moisture in this region, i.e. dry locations outnumbered wet locations (Fig. 5). As spacing increases, the proportions of dry locations would decrease less than the wet locations. Dry locations are more temporally stable in this desert region, i.e. have lower SDRDs (Zhang and Shao, 2013), so we observed a different response rate of the minimum and maximum SDRD to the increase in spacing. The mean SDRD decreased with increasing spacing (Fig. 4c), which could be described with an exponential equation $(p<0.01)$. The ANOVAs, however, found no significant differences in mean SDRD between the various spacings ( $p>0.05$, Table 1$)$. These results indicate, in agreement with Blöschl and Grayson (2000) and Molina et al. (2014), that the increase in spacing does not affect the characteristics of temporal stability at the location scale, i.e. does not weaken the ability of individual locations to determine field-mean soil-moisture content. This finding also confirmed the Spearman's rank correlation test that the temporal stability of the spatial patterns of soil moisture did not change with the spacing.

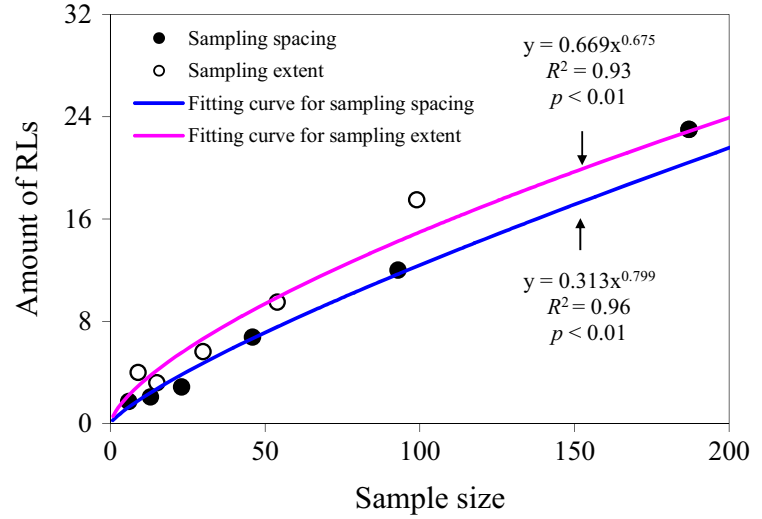

Fig. 8. Changes in the number of representative locations (RLs) as a function of sample size at various sampling spacings and extents.

As sampling extent increased, the minimum SDRD decreased and the maximum and range of SDRD increased (Table 1 and Fig. $4 \mathrm{e}-\mathrm{h}$ ). The minimum SDRD, though, had a logarithmic relationship with extent, and both the maximum and range of SDRD had a power function with extent (Fig. $4 \mathrm{e}-\mathrm{h}$ ). These results can be attributed to the fact that both the more and less stable locations are gradually included as extent increases. The mean SDRD tended to increase with increasing extent, and this trend could be well fitted by a power function (Fig. $4 \mathrm{~g}$ ). Increasing the extent may thus tend to decrease the temporal stability at the individual locations. As the extent increases, the factors influencing soil moisture may become increasingly complex and variable, leading to stronger fluctuations of soil-moisture content between individual locations and the field-mean moisture content over time.

SDRD was also characterised by testing its link to MRD at different spacings and extents to understand the relative temporal stabilities under dry or wet conditions. SDRD was positively correlated with MRD for all sampling scales (Fig. 6), indicating a
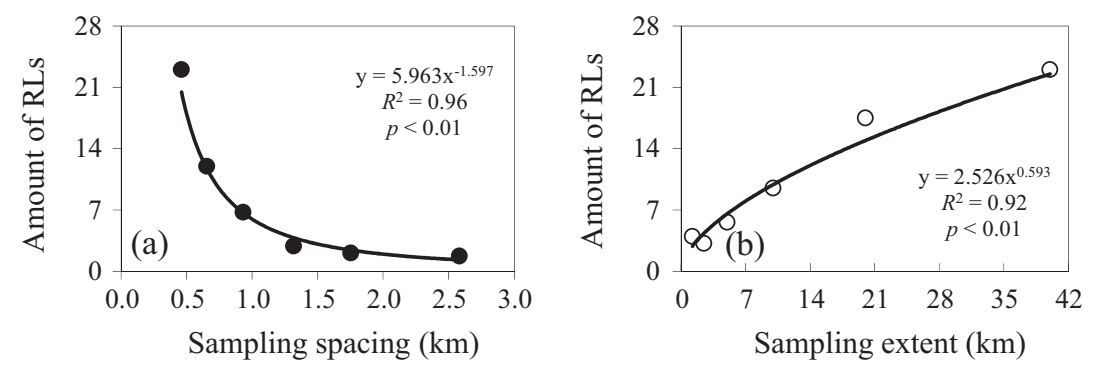

Fig. 7. Changes in the number of representative locations (RLs) as a function of sampling spacing (a) and extent (b). 
declining trend of temporal stability of soil moisture with increasing soil wetness. The magnitude of the positive correlation decreased linearly $(p<0.01$, Fig. 6a) as spacing increases, and increased logarithmically ( $p<0.01$, Fig. 6b) as extent increases. These trends imply that the dependence of temporal stability on the conditions of soil wetness will increase as the spacing gets smaller or the extent gets larger.

\subsection{Influence of sampling scale on the identification of representative locations}

The main purpose of measuring temporal stability is to identify representative locations (RLS) for precisely estimating the field-mean moisture content. Zhang and Shao (2013) compared and evaluated different methods for representing the field mean and found that a low SDRD played a more important role than a near-zero MRD for estimating field means, and a low SDRD with a constant offset (Eq. (6)) was the best tool for estimating field means in this desert region. We therefore selected the sampling locations with SDRDs $<10 \%$ as the RLs for each sampling scale.

The number of RLs generally decreased (Table 2) regardless of the increase in spacing or the decrease in extent, which were both mainly due to the gradually reduced sample size. With spacing, for example, the number of RLs decreased from 23 to 2 when the sample size fell from 187 to 6 (Table 2). Because reductions in sample size cannot continue indefinitely, the rate of decrease in the number of RLs gradually slowed as spacing increased, and the decreasing trend could be described by a power function $(p<0.01)$, which was also applied to the extent, as shown in Fig. 7. We further analysed the number of RLs at different spacings and extents to clarify the influence of sample size. The number of RLs were positively correlated with sample size with a power-function relationship
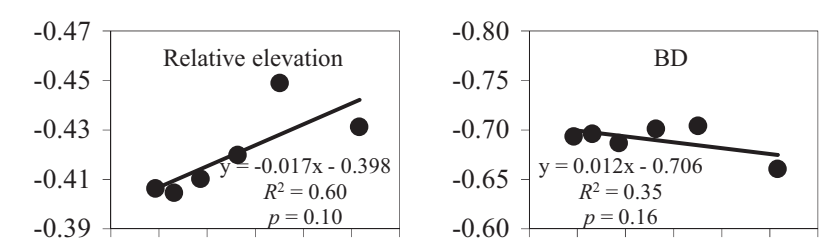

$\begin{array}{llllllll}0.0 & 0.5 & 1.0 & 1.5 & 2.0 & 2.5 & 3.0\end{array}$
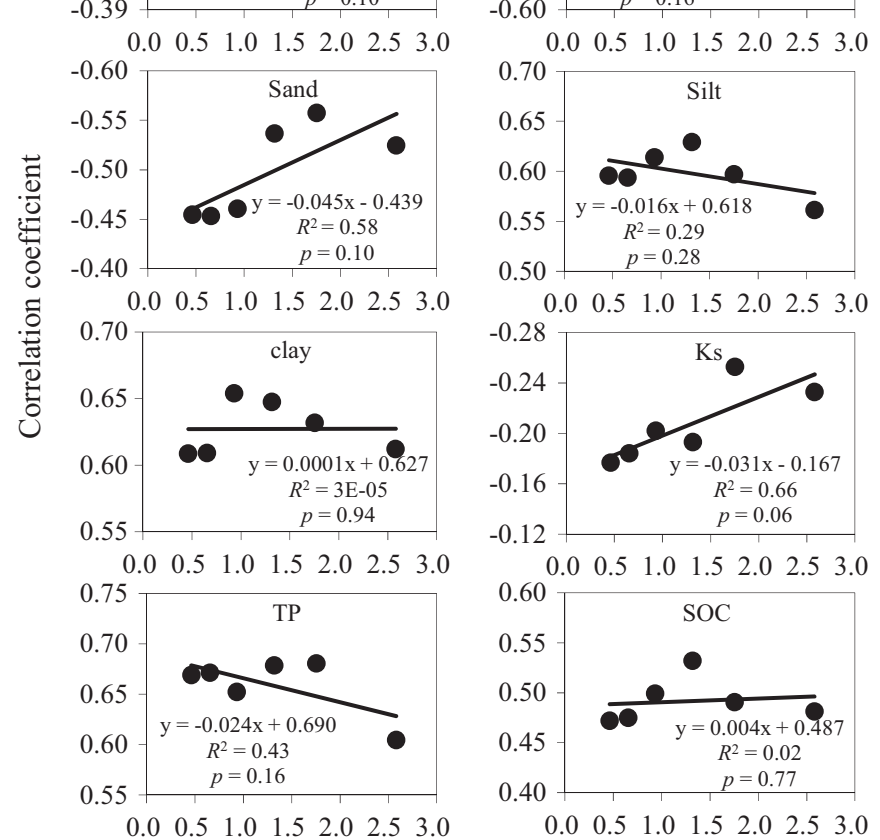

$\begin{array}{llllllll}0.0 & 0.5 & 1.0 & 1.5 & 2.0 & 2.5 & 3.0\end{array}$
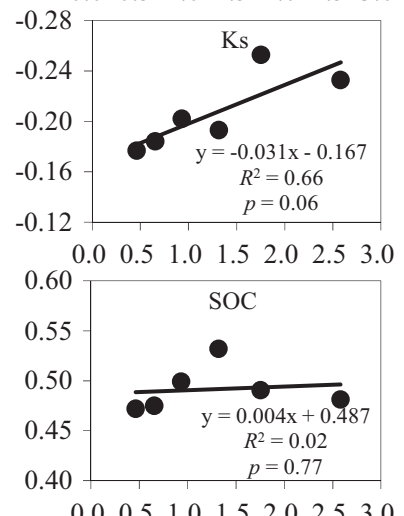

Sampling spacing $(\mathrm{km})$ for both spacing and extent ( $p<0.01$, Fig. 8 ). The rate of increase in the number of RLs with sample size was much higher for extent than for spacing within the ranges of this study (Fig. 7). In other words, the number of RLs will increase more with decreasing spacing than with increasing extent for identical increases in sample size. These results imply that the number of RLs is more sensitive to changes in sample size caused by extent than to changes caused by spacing, which would have great significance for the design of sampling schemes.

To test the ability of the identified RLs to accurately represent the field mean, the measured soil-moisture contents at the RLs were first applied with a constant offset (Eq. (6)) to give the average field mean and were then compared with the observed field mean. The RMSEs are given in Table 2. Estimates are accurate at RMSEs $<2 \%$ (Cosh et al., 2008), and even though the number of identified RLs in our study varied with spacing and extent, all sets of selected RLs were able to accurately estimate the field mean (RMSE $<0.50 \% \mathrm{vol} / \mathrm{vol}$ ) for the entire period by using the offset estimate method (Table 2). The RLs were thus appropriate for estimating field mean with an acceptable degree of accuracy at any sampling scale. The RMSE, however, did not have a clear relationship with sampling scale in either spacing or extent, indicating that a change in sampling scale cannot weaken/intensify the ability of RLs to estimate the field mean. The measurement of soil-moisture content at many RLs is costly in time and money, so we further tested the ability of a single sampling location (the most temporally stable RL) to estimate the field mean. The RMSEs of the most stable RLs were low $(0.23-0.50 \% \mathrm{vol} / \mathrm{vol}$, Table 2), implying that a single sampling location could characterise the field mean. Compared to averaging all the RLs, using only the most temporally stable RL increased the RMSE considerably, in agreement with Schneider et al. (2008). Soil moisture was not
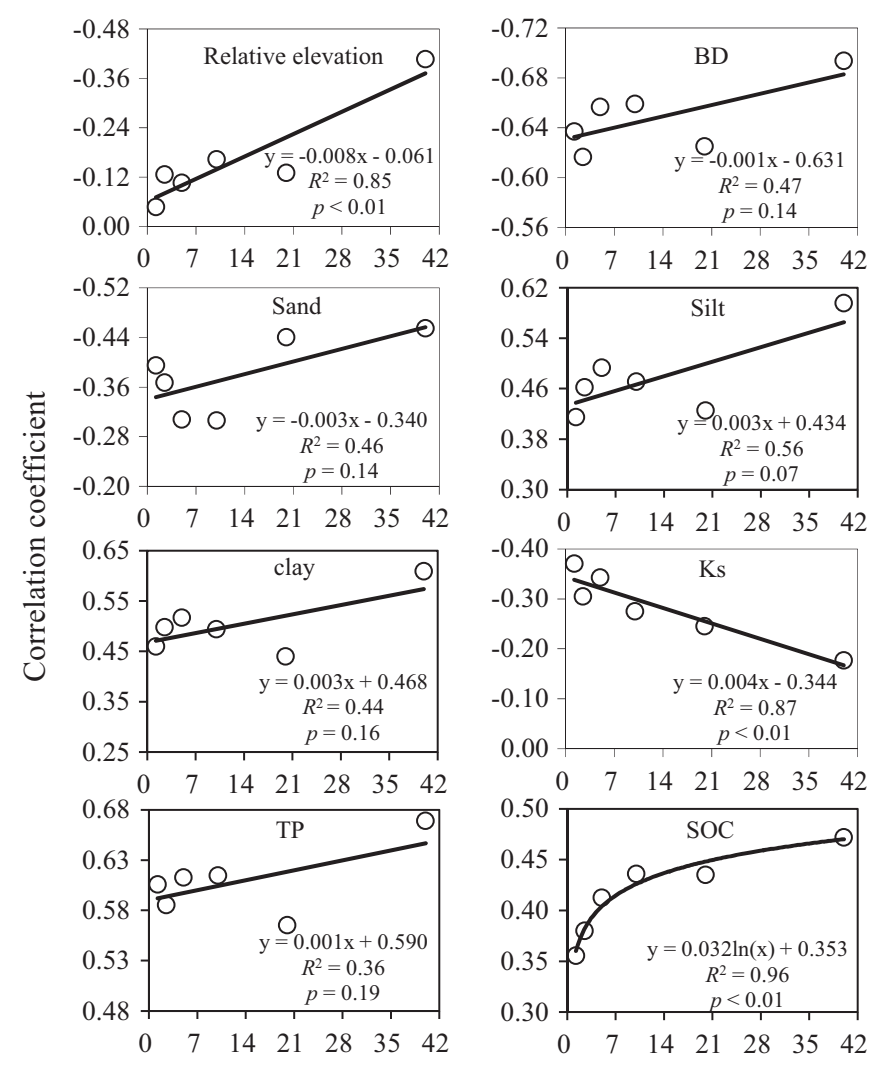

Sampling extent $(\mathrm{km})$

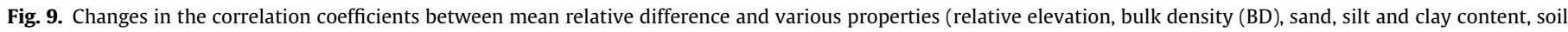
saturated hydraulic conductivity (Ks), total porosity (TP), and soil organic carbon content (SOC)) as a function of sampling spacing and extent. 


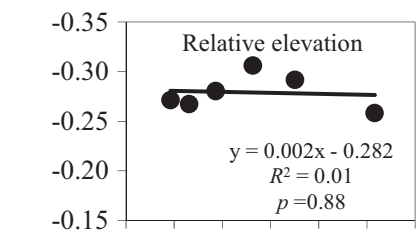

$\begin{array}{llllllll}0.0 & 0.5 & 1.0 & 1.5 & 2.0 & 2.5 & 3.0\end{array}$

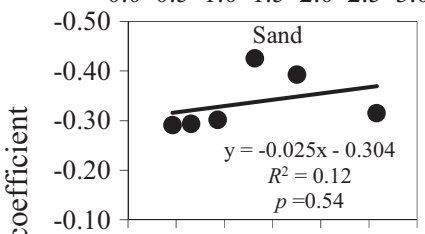

$\begin{array}{llllllll}0.0 & 0.5 & 1.0 & 1.5 & 2.0 & 2.5 & 3.0\end{array}$

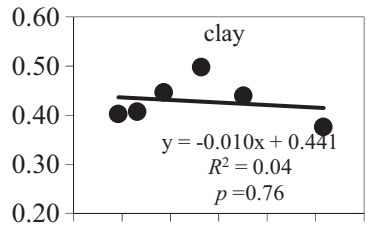

$\begin{array}{lllllll}0.0 & 0.5 & 1.0 & 1.5 & 2.0 & 2.5 & 3.0\end{array}$

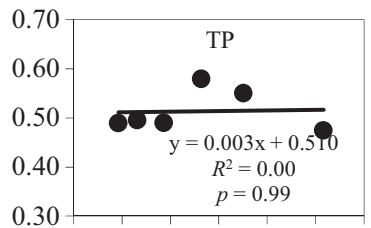

$\begin{array}{lllllll}0.0 & 0.5 & 1.0 & 1.5 & 2.0 & 2.5 & 3.0\end{array}$

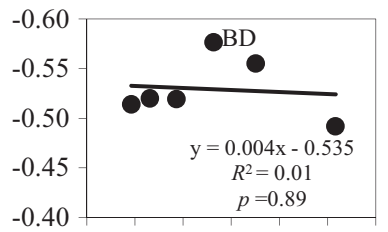

$\begin{array}{lllllll}0.0 & 0.5 & 1.0 & 1.5 & 2.0 & 2.5 & 3.0\end{array}$

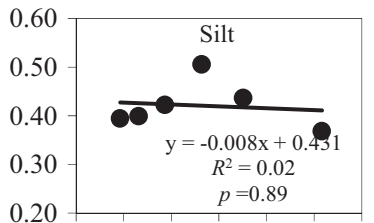

$\begin{array}{llllllll}0.0 & 0.5 & 1.0 & 1.5 & 2.0 & 2.5 & 3.0\end{array}$

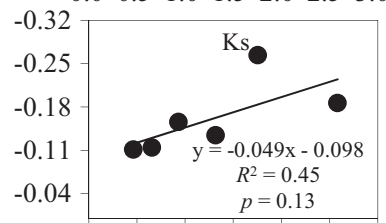

$\begin{array}{llllllll}0.0 & 0.5 & 1.0 & 1.5 & 2.0 & 2.5 & 3.0\end{array}$

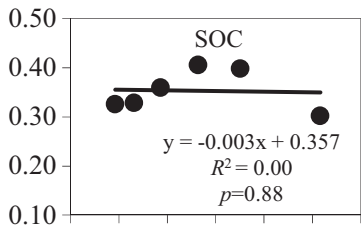

$\begin{array}{llllllll}0.0 & 0.5 & 1.0 & 1.5 & 2.0 & 2.5 & 3.0\end{array}$

Sampling spacing $(\mathrm{km})$
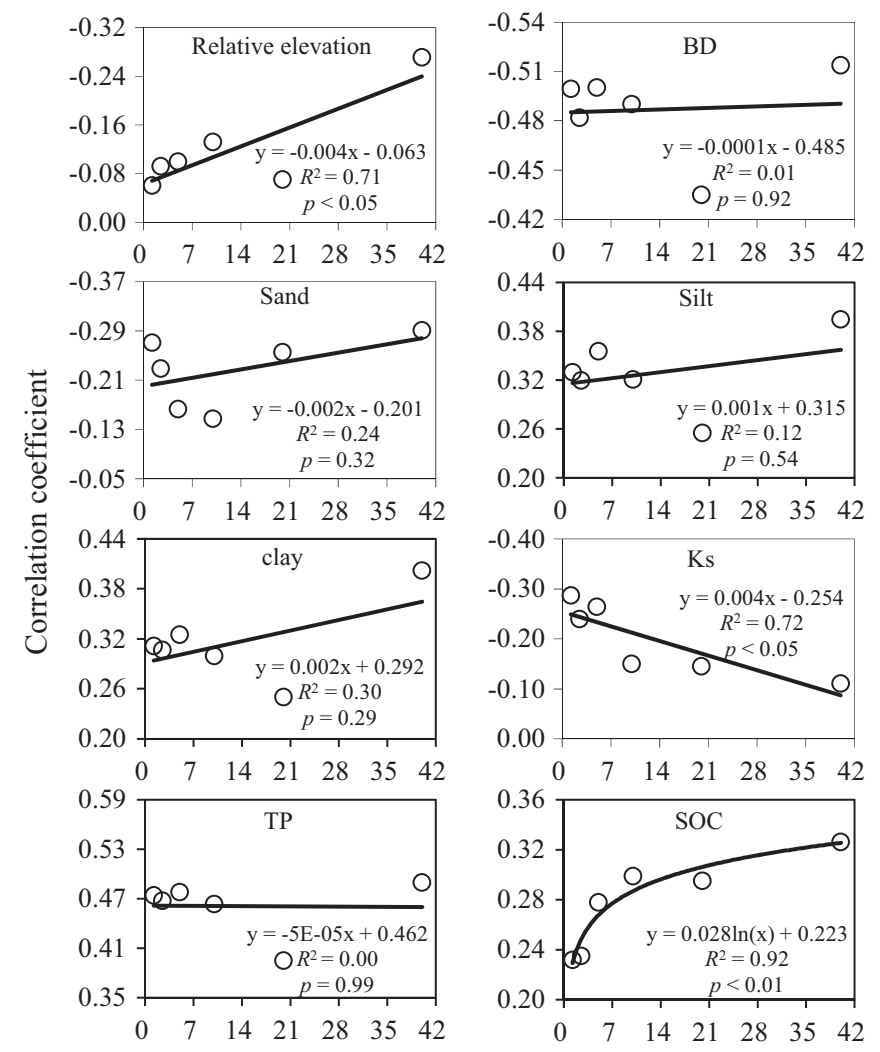

Sampling extent $(\mathrm{km})$

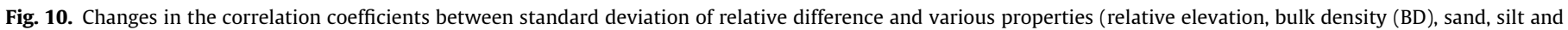
clay content, soil saturated hydraulic conductivity (Ks), total porosity (TP), and soil organic carbon content (SOC)) as a function of sampling spacing and extent.

measured at exactly the same sites on different sampling dates, so the minimum RMSE that can be obtained with a single temporally stable location is restricted by the replication of the moisture measurements at each location (Schneider et al., 2008).

\subsection{Influence of sampling scale on the factors affecting the temporal stability of soil moisture}

The contributions of topography and soil properties to the temporal stability were investigated by testing the correlation coefficients between MRD and SDRD versus the potentially associated properties, and the changes in the correlation coefficient with increasing sampling spacing and extent are shown in Figs. 9 and 10. The correlations between MRD and SDRD versus relative elevation, BD, soil texture (i.e., sand, silt and clay content), Ks, $\mathrm{TP}$, and SOC content were not affected by changes in spacing, indicating that the role of these properties in influencing the temporal stability did not vary with spacings.

Like the spacing, increasing the sampling extent did not change the role of $\mathrm{BD}$, soil texture, and TP in influencing the temporal stability, as shown by the nearly constant correlations between MRD and SDRD versus these properties over the complete range of scales (Figs. 9 and 10). The relatively higher correlation with MRD and SDRD thus suggests that these soil properties are important in controlling temporal stability at all scales. In contrast, the correlations between MRD and SDRD versus other properties (relative elevation, Ks and SOC content) were affected by changes in extent. The magnitude of the correlations with relative elevation and SOC content significantly increased, and the correlation with Ks significantly decreased as extent increased (Figs. 9 and 10). These results suggest that the relative significance of these properties in regulating the temporal stability may vary with extents. The relative elevation can be reasonably expected to influence the temporal stability in larger scales of extent because of the increasingly diverse and complex topography as extent increases. Moreover, the distribution of SOC content in this region is highly dependent on the mineralogical composition of the parental material and on the weathering processes that have led to its formation (Zhang and Shao, 2015). As extent increases and parental material and climate become more heterogeneous, the influence of SOC content on temporal stability will become more significant. On the contrary, the influence of Ks on soil moisture is mainly through its impact on soil saturation and drainage (Gao and Shao, 2012). It may significantly influence the temporal stability at a small scale of extent, but the influence may be weakened as extent increases.

\section{Conclusions}

Surface-soil $(0-6 \mathrm{~cm})$ moisture contents were measured from 15 April to 15 October 2012 roughly bi-weekly in a desert area in northwestern China. The effects of various sampling scales (spacing and extent) on the characteristics of temporal stability were examined using a re-sampling technique, and the following conclusions were drawn:

(1) The characteristics of the temporal stability of surface-soil moisture were generally strongly scale-dependent. Specifically, increasing sampling spacing had little influence on the characteristics of temporal stability of both the overall spatial pattern and the individual locations, whereas increasing sampling extent tended to increase the temporal stability of the overall spatial pattern but to decrease the 
temporal stability at the individual locations. Moreover, the temporal stability was susceptible to scale changes at lower extents.

(2) The specific patterns of scale dependency differed among the parameters of temporal stability. But generally, an exponential equation could well express the relationships between most of the statistical parameters and spacing, whereas a power equation could well express the relationships between most of the statistical parameters and extent.

(3) The number of RLs decreased as spacing increased or extent decreased due to the reduction in sample size, and the number of RLs was more sensitive to changes in sample size caused by extent than by those caused by spacing.

(4) At any sampling scale, the field-mean moisture content could be estimated with an acceptable degree of accuracy by measurements at a limited number of locations (i.e. the RLs), even at a single location. The estimate accuracy was not affected by sampling scale.

(5) Increasing the spacing did not change the influence of topography and soil properties (relative elevation, BD, soil texture, Ks, TP, and SOC content) on temporal stability, whereas increasing the extent tended to intensify the influence of relative elevation and SOC but to weaken the influence of Ks on temporal stability.

These findings are useful but are likely not universally applicable. Many more studies in a variety of regions and environments are needed to understand the scale dependence of temporal stability.

\section{Acknowledgements}

This study was financially supported by the Major Program of the National Natural Science Foundation of China (No. 91025018) and the Foundations from Chinese Academy of Sciences (KZCX2-XB3-13). Special thanks go to the staff of the Linze Inland River Basin Research Station of the Institute of Cold and Arid Regions Environmental and Engineering Research of CAS.

\section{References}

Berndtsson, R., Nodomi, K., Yasuda, H., Persson, T., Chen, H., Jinno, K., 1996. Soil water and temperature patterns in an arid desert dune sand. J. Hydrol. 185, $221-240$.

Biswas, A., Si, B.C., 2011. Scales and locations of time stability of soil water storage in a hummocky landscape. J. Hydrol. 408, 100-112.

Blöschl, G., Grayson, R.B., 2000. Spatial observations and interpolation. In: Grayson, R.B., Blöschl, G. (Eds.), Spatial Patterns in Hydrology. Cambridge Univ. Press, Cambridge, UK, pp. 17-50.

Blöschl, G., Sivapalan, M., 1995. Scale issues in hydrological modelling: a review. Hydrol. Process. 9, 251-290.

Bosch, D.D., Lakshmi, V., Jackson, T.J., Choi, M., Jacobs, J.M., 2006. Large scale measurements of soil moisture for validation of remotely sensed data: Georgia soil moisture experiment of 2003. J. Hydrol. 323, 120-137.

Brocca, L., Melone, F., Moramarco, T., Morbidelli, R., 2009. Soil moisture temporal stability over experimental areas in Central Italy. Geoderma 148, 364-374.

Brocca, L., Tullo, T., Melone, F., Moramarco, T., Morbidelli, 2012. Catchment scale soil moisture spatial-temporal variability. J. Hydrol. 422, 63-75.

Choi, M., Jacobs, J.M., 2007. Soil moisture variability of root zone profiles within SMEX02 remote sensing footprints. Adv. Water Resour. 30, 883-896.

Coppola, A., Comegna, A., Dragonetti, N., Kader, A., Comegna, V., 2011. Average moisture saturation effects on temporal stability of soil water spatial distribution at field scale. Soil Till. Res. 114, 155-164.

Cosh, M.H., Jackson, T.J., Bindlish, R., Prueger, J.H., 2004. Watershed scale temporal and spatial stability of soil moisture and its role in validating satellite estimates. Rem. Sens. Environ. 92, 427-435.

Cosh, M.H., Jackson, T.J., Starks, P., Heathman, G., 2006. Temporal stability of surface soil moisture in the Little Washita River watershed and its applications in satellite soil moisture product validation. J. Hydrol. 323, 168-177.
Cosh, M.H., Jackson, T.J., Moran, S., Bindlish, R., 2008. Temporal persistence and stability of surface soil moisture in a semi-arid watershed. Rem. Sens. Environ. 112, 304-313.

Famiglietti, J.S., Ryu, D., Berg, A.A., Rodell, M., Jackson, T.J., 2008. Field observations of soil moisture variability across scales. Water Resour. Res, 44, W01423.

Gao, L., Shao, M.A., 2012. Temporal stability of shallow soil water content for three adjacent transects on a hillslope. Agric. Water Manage. 110, 41-54.

Grayson, R.B., Western, A.W., 1998. Towards areal estimation of soil water content from point measurements: time and space stability of mean response. J. Hydrol 207, 68-82.

Heathman, G.C., Cosh, M.H., Merwade, V., Han, E., 2012. Multi-scale temporal stability analysis of surface and subsurface soil moisture within the Upper Cedar Creek Watershed, Indiana. Catena 95, 91-103.

Hu, W., Shao, M.A., Han, F.P., Reichardt, K., Tan, J., 2010. Watershed scale temporal stability of soil water content. Geoderma 158, 181-198.

Jia, Y.H., Shao, M.A., 2013. Temporal stability of soil water storage under four types of revegetation on the northern Loess Plateau of China. Agric. Water Manage. 117, 33-42.

Kachanoski, R.G., Jong, E., 1988. Scale dependence and the temporal persistence of spatial patterns of soil water storage. Water Resour. Res. 24, 85-91.

Klute, A., Dirksen, C., 1986. Hydraulic conductivity of saturated soils. In: Klute, A. (Ed.), Methods of Soil Analysis. ASA and SSSA, Madison, Wisconsin, USA, pp. 694-700.

Martínez-Fernández, J., Ceballos, A., 2003. Temporal stability of soil moisture in a large-field experiment in Spain. Soil Sci. Soc. Am. J. 67, 1647-1656.

Mittelbach, H., Seneviratne, S.I., 2012. A new perspective on the spatio-temporal variability of soil moisture: temporal dynamics versus time-invariant contributions. Hydrol. Earth Syst. Sci. 16, 2169-2179.

Mohanty, B.P., Skaggs, T.H., 2001. Spatio-temporal evolution and time-stable characteristics of soil moisture within remote sensing footprints with varying soil, slope, and vegetation. Adv. Water Resour. 24, 1051-1067.

Molina, A.J., Latron, J., Rubio, C.M., Gallart, F., Llorens, P., 2014. Spatio-temporal variability of soil water content on the local scale in a Mediterranean mountain area (Vallcebre, North Eastern Spain). How different spatio-temporal scales reflect mean soil water content. J. Hydrol. 516, 182-192.

Nelson, D.W., Sommers, L.E., 1982. Total carbon, organic carbon and organic matter In: Page, A.L., Miller, R.H., Keeney, D.R. (Eds.), Methods of Soil Analysis. Part 2. Agronomy Monograph, second ed. ASA and SSSA, Madison, WI, pp. 534-580.

Penna, D., Brocca, L., Borga, M., Dalla Fontana, G., 2013. Soil moisture temporal stability at different depths on two alpine hillslopes during wet and dry periods. J. Hydrol. 477, 55-71.

Ran, Y.H., Li, X., Wang, W.Z., Jin, R., 2009. Grid scale temporal stability of multilayer soil moisture in a grassland ecosystem in western China. Adv. Earth Sci. 24, 817-824 (in Chinese).

Rodriguez-Iturbe, I., D’odorico, P., Porporato, A., Ridolfi, L., 1999. On the spatial and temporal links between vegetation, climate, and soil moisture. Water Resour Res. 35, 3709-3722.

Schneider, K., Huisman, J.A., Breuer, L., Zhao, Y., Frede, H.G., 2008. Temporal stability of soil moisture in various semi-arid steppe ecosystems and its application in remote sensing. J. Hydrol. 359, 16-29.

Starks, P.J., Heathman, G.C., Ahuja, L.R., Ma, L., 2003. Use of limited soil property data and modeling to estimate root zone soil water content. J. Hydrol. 272, 131 147.

Sur, C., Jung, Y., Choi, M., 2013. Temporal stability and variability of field scale soil moisture on mountainous hillslopes in Northeast Asia. Geoderma 207, 234 243.

Thornes, J.B., 1985. The ecology of erosion. Geography, 222-235.

Vachaud, G., Passerat de Silans, A., Balabanis, P., Vauclin, M., 1985. Temporal stability of spatially measured soil water probability density function. Soil Sci. Soc. Am. J. 49, 822-828.

Vanderlinden, K., Vereecken, H., Hardelauf, H., Herbst, M., Martínez, G., Cosh, M.H., Pachepsky, Y.A., 2012. Temporal stability of soil water contents: a review of data and analyses. Vadose Zone J. 11 (4).

Vereecken, H., Kamai, T., Harter, T., Kasteel, R., Hopmans, J., Vanderborght, J., 2007 Explaining soil moisture variability as a function of mean soil moisture: a stochastic unsaturated flow perspective. Geophys. Res. Lett. 34, L22402.

Vereecken, H., Huisman, J.A., Pachepsky, Y., Montzka, C., van der Kruk, J., Bogena, H. Weihermüller, L., Herbst, M., Martinez, G., Vanderborght, J., 2014. On the spatiotemporal dynamics of soil moisture at the field scale. J. Hydrol. 516, 76-96.

Western, A.W., Blöschl, G., 1999. On the spatial scaling of soil moisture. J. Hydrol. 217, 203-224.

Zhang, P., Shao, M.A., 2013. Temporal stability of surface soil moisture in a desert area of northwestern China. J. Hydrol. 505, 91-101.

Zhang, P., Shao, M.A., 2015. Spatiotemporal variability of surface-soil water content and its influencing factors in a desert area, China. Hydrol. Sci. J. 60 (1), 96-110.

Zhao, Y., Peth, S., Wang, X.Y., Lin, H., Horn, R., 2010. Controls of surface soil moisture spatial patterns and their temporal stability in a semi-arid steppe. Hydrol. Process 24, 2507-2519. 